\title{
EMERGÊNCIA DAS QUESTÕES AMBIENTAIS NA VIRADA EPISTEMOLÓGICA: REFLEXÕES E TESSITURAS SOBRE O SUJEITO DA MODERNIDADE
}

\author{
Frederico Castro Carvalho ${ }^{1}$ \\ Idelvon da Silva Poubel ${ }^{2}$
}

\begin{abstract}
Resumo: Vários campos do conhecimento durante muito tempo se ativeram às discussões focadas no plano das relações sociais, às lutas de classe, às consequências oriundas do capitalismo e da industrialização em detrimento às questões ambientais, ou seja, sem considerar o ambiente nos quais essas relações eram e são tecidas. Dessa forma podemos refletir e pensar nas várias discussões acerca de como veio sendo construída e constituída as noções de "ambiental", "ecologia", e preocupações com o meio ambiente advindos dessa inquietação que se perpassa na atualidade - 0 "aquecimento global", temática essa que se agiganta cada vez mais em todos os setores da sociedade. As considerações dos intelectuais contemporâneos têm se refletido sobre as relações sociedade e natureza na modernidade tardia e nas caracterizações de cientistas políticos e sociais sobre a evolução das políticas ambientais e suas consequências nos países industrializados e no Brasil. Sendo assim, a intenção deste estudo é discutir a estreita relação entre as questões ambientais e a sociedade, elencando questionamentos que possam suscitar temáticas alusivas à Educação Ambiental.
\end{abstract}

Palavras-chave: Epistemologia; Educação Ambiental; Dinâmicas sociais

\footnotetext{
${ }^{1}$ Instituto Federal de Educação, Ciência e Tecnologia do Espírito Santo.

E-mail: frederico.castro@ifes.edu.br

${ }^{2}$ Secretaria Municipal de Meio Ambiente de Vitória (ES). E-mail: idelvonpoubel@yahoo.com.br
}

Revbea, São Paulo, V. 10, N 1: 84-93, 2015. 


\section{Introdução}

A emergência ${ }^{3}$ do ambientalismo contemporâneo está pautada nas dinâmicas sociais, constituídas a partir do modo de produção vigentes que tem provocado e demandado a criação de instituições, legislações e políticas públicas voltadas para novas pautas e, assim, modificando formas tradicionais ligadas às relações entre sociedade e natureza, entre elas, as discussões sobre as relações homem-meio, recursos naturais, apropriação das paisagens e dos espaços.

Esse estudo começa com um questionamento inquietante e, ao mesmo tempo, motivador/fomentador das principais discussões sócio-ambientais: $A$ sociedade humana está diante de uma crise ambiental ou de uma crise de paradigmas?

Para buscar possíveis respostas ou ampliar a problematização que se instala, há que se construir uma reflexão partindo do atual contexto histórico, em que a globalização está longe de permitir eqüitativa melhoria da qualidade de vida dos cidadãos, a questão ambiental se apresenta como um dos desafios mais importantes a se enfrentar. A todo o momento multiplicam-se as informações acerca dos impactos ambientais e suas conseqüências. As temáticas relacionadas ao meio ambiente (como se o meio ambiente fosse descolado das relações sociais e seus frutos: trabalho, lazer, violência, fome, guerras!) ocupam espaço cada vez maior nos meios de comunicação, nos círculos acadêmicos e na sociedade como um todo, transpassando os cenários e as paisagens cotidianas de vivência do sujeito/humano, conclamando-o, alertando-o, às vezes de forma apelativa e às vezes sem critérios, sobre o seu papel como "cidadão".

A questão ambiental não reconhecida e não levada em consideração pelos modelos pretéritos de produção e crescimento econômico realizado nos países desenvolvidos e almejado pelos "em desenvolvimento", transcende os limites de sua inserção inicial para se tornar uma preocupação permanente em todas as esferas do conhecimento na atual "sociedade de risco",, conceito cunhado por Beck (1997) e analisado por Giddens (1997, apud BECK, GIDDENS e LASH, 1997, p. 274), onde "[...] os problemas ecológicos expõem todas [... as] dificuldades que um capitalismo, aparentemente triunfante, traz

\footnotetext{
${ }^{3} \mathrm{Na}$ construção do seu pensamento à cerca da complexidade Morin (1997) argumenta que as emergências são "[...] qualidades que nascem das associações e das combinações [...]" (p.104) entre o todo e as partes e que as imposições correspondem ao "[...] determinismo complexo, as regras, as regularidades, a subordinação dos componentes ao todo, o ajustamento das complementaridades, as especializações, a retroação do todo, a estabilidade do todo, e, nos sistemas vivos, os dispositivos de regulação e de controlo [...]" (p. 109). Dessa forma as partes estão em contato contínuo estabelecendo múltiplas relações que não podem ser entendidas quando pensadas isoladamente, pois a parte não representa o todo e nem o todo e a mera soma das partes.

${ }^{4}$ Encontro em Beck (1997) uma conceituação muito interessante acerca da obsolescência da sociedade industrial na "modernização reflexiva", fazendo emergir, segundo o sociólogo, a "sociedade de risco". "Este conceito designa uma fase no desenvolvimento da sociedade moderna, em que os riscos sociais, políticos, econômicos e individuais tendem cada vez mais a escapar das instituições para o controle e a proteção da sociedade industrial' (apud BECK, GIDDENS e LASH, 1997, p. 15).
}

Revbea, São Paulo, V. 10, № 1: 84-93, 2015. 
em seu rastro", consolidando-se um fenômeno global, construído por diversas dimensões interdependentes sobre os quais debruçam governos, pesquisadores, empresas, instituições e organizações não-governamentais.

Milton Santos (1997, p. 27), em as "Metamorfoses do Espaço Habitado", argumenta que este é um "Período Técnico-Científico-Informacional", onde o espaço é historicamente construído a partir da intervenção humana e das apropriações das disponibilidades materiais e imateriais desse espaço.

A partir de uma visão economicista por parte da espécie humana, o meio ambiente sempre foi concebido como "recurso". Nesta perspectiva, o homem é visto como um ser desvinculado de todas as dimensões que justamente o diferenciam dos demais seres vivos. Dentre estas estão as aspirações místicoreligiosas, afinidades étnicas, identidades sociais e muitas outras. Uma série de demandas reais é igualmente omitida pela visão economicista, como a necessidade de ar puro, de água que realmente atenda os critérios de potabilidade, habitação adequada e alimentação sadia.

Dessa forma, as preocupações com o aumento das médias nas temperaturas do planeta constatadas pelos cientistas, têm se tornado um incômodo para os líderes mundiais que, com mais frequência, se reúnem buscando discutir possibilidades de diminuição do aquecimento global, a partir das intervenções que esse "homem" tem provocado. A necessidade de se obter fontes de energia mais eficientes e menos poluentes para atender à demanda industrial, bem como o crescimento das economias dos países, tem sido ponto de pauta e desafio para os governantes.

Ao longo da história a sociedade capitalista tem usufruído e se apropriado de maneira hostil dos elementos encontrados na natureza. Desde os primórdios ela tem buscado novas formas de satisfazer suas necessidades extraindo do meio natural tudo o que lhe apraz. Com o aumento da população e o desenvolvimento de novas tecnologias aumentou-se também a demanda, 0 consumismo, a irresponsabilidade, o desprezo às formas racionalizadas de consumo, em detrimento à consciência ético-ecológica. Tais fatos têm levado esse ser humano provido de "maior capacidade de pensar" a agir em um nível inapropriado de uso do meio ambiente, degenerando-o.

Bourdieu (1989), em O Poder Simbólico, alerta que as pretensões do homem em dominar a natureza, consistiam em, ao fazê-la, dominar o próprio homem, numa relação de poder que se reproduzia como instrumento de dominação nas sociedades ocidentais. O início da extração antiecológica de minerais e de madeiras é registrado com mais intensidade a partir de fins do século XVIII com o advento da Revolução Industrial, ocorrida no Reino Unido, espalhando-se posteriormente para o resto do mundo, sendo estes fatores fundamentais para o início da degradação ambiental. Notadamente os países mais desenvolvidos, tidos como os mais industrializados são também os campeões em degradação e poluição, são aquele que, ao custo do seu desenvolvimento e da sua industrialização exauriram suas reservas de "recurso naturais", comprovando, assim, o que ensinou Bourdieu.

Revbea, São Paulo, V. 10, N 1: 84-93, 2015. 
O "boom" da Revolução Verde em meados do século XX, forjado na utilização dos recursos tecnológicos sendo aplicados na produção agropecuária, com uso abusivo e indiscriminado de agrotóxicos e fertilizantes industriais visando o aumento da produtividade, incentivaram/incentivam ainda mais o consumismo irresponsável e também é um indicador contribuinte na escalada dessa forma predatória de apropriação dos elementos naturais visualizados nas paisagens. Somados à crescente urbanização sem o devido planejamento, à emissão de gases poluentes expelidos por veículos automotores e indústrias, que alcançariam proporções alarmantes, esses fatores têm gerado graves problemas ambientas sentidos em escala planetária e que afetam direta e indiretamente a todas as formas de vida.

Essa gama de situações fez/faz emergir tensões num momento marcado pela crise paradigmática ${ }^{5}$. Boaventura Santos $(2000$, p.74) ensina que essa crise é tida como o período de transição do paradigma dominante, conhecido como paradigma da modernidade ocidental, marcado por uma sociedade patriarcal assentada no modo de produção capitalista, no consumismo individualista e mercadorizado, na identidade-fortaleza, na democracia autoritária e no desenvolvimento desigual e excludente, para o paradigma emergente ${ }^{6}$, designado como "[...] paradigma de um conhecimento prudente para uma vida descente", onde se "[...] valoriza o conhecimento do senso comum com que no cotidiano orientamos nossas ações e damos sentido à nossa vida" (SANTOS, 1987, apud CARVALHO, 2004, p.19), visando solidariedade e o princípio de comunidade.

Jeffrey Alexander (1987), em o "Novo Movimento Teórico" traz como contribuição ao debate as relações dialéticas existentes entre 0 micro e 0 macro, a fim de tentar estabelecer um marco de análise ao longo da constituição do campo investigativo e discursivo do saber, ajudando-nos a pensar nas as formas de atuação local, com resultantes em nível global.

Apesar de não falar explicitamente acerca das relações entre os sujeitos e o ambiente de vivência destes, Berger e Luckmann (1985) afirmam que a construção social da realidade se processa a partir das interações sociais partilhadas na vida cotidiana. Por certo estas interações ocorrem em um espaçotempo por meios de "esquemas tipificados" que acontecem a todo o momento deixando nesses sujeitos e, por conseguinte, nos espaços por ele vivenciados, as marcas dessas relações, tendo como testemunhas as

\footnotetext{
${ }^{5}$ Tomo aqui emprestado o que ensina Capra (1988, p. 17): “[...] paradigma significa a totalidade de pensamentos, percepções e valores que formam uma determinada visão da realidade, uma visão que é a base do modo como a sociedade se organiza e que se constitui como referencial de análise e interpretação de uma realidade".

${ }^{6}$ Carvalho (2004, p.17-18), a partir do estudo dos trabalhos de Boaventura Santos, afirma que "enquanto o paradigma dominante se define pelas características da racionalidade cognitivo-instrumental da ciência moderna, apresentando um saber pronto, fechado em si mesmo, um produto organizado e estruturado sequencialmente que deva ser transmitido em tópicos menores, regido pela lógica de reprodução do conhecimento, o paradigma emergente se definiria pela concepção de conhecimento como espaço conceitual, no qual os agentes constroem um saber novo, produto sempre contraditório, inacabado, de processos sociais, históricos, culturais e psicológicos".
} 
alterações nas partes visíveis desses espaços, que são as paisagens, constituídas a partir de acúmulos de tempos desiguais (SANTOS, 2004).

Morin (1996), cuja teoria busca desenvolver o pensamento vislumbrando o entendimento do mundo a partir da complexidade, considera que a atual crise, entre outros fatores adicionados, advém da exagerada fragmentação do conhecimento, que acaba dificultando a comunicação, tornando impossível o conhecimento do conhecimento.

O problema da complexidade tornou-se uma exigência social e política vital no nosso século: damo-nos conta de que o pensamento mutilante, isto é, o pensamento que se engana, não porque não tem informação suficiente, mas porque não é capaz de ordenar as informações e os saberes, é um pensamento que conduz a ações mutilantes (MORIN, 1996, p.14)

\section{O SUJEITO DA MODERNIDADE LÍQUIDA}

As discussões e as reflexões aqui tecidas se traduzem no ponto de partida para se pensar como a ciência moderna poderia/pode ajudar o ser humano a resolver os problemas por ele mesmo causado/criado, como o aquecimento global, a fome, as guerras, a violência.

Boaventura Santos (2000, p. 75) alerta,

[...] antes de mais, que só a partir da modernidade é possível transcender a modernidade. Se é verdade que a modernidade não pode fornecer a solução para excessos e déficits por que é responsável, não é menos verdade que só ela permite desejála. De fato, podemos encontrar na modernidade tudo o que é necessário para formular uma solução, tudo menos essa solução.

Pensando nas consequências geradas no seio dessa discussão, tornase possível elencar dimensões variadas, política, educacional, econômica, etc., que se estabelecem na sociedade atual alcançada e atravessada a partir da dinamicidade com que os eventos vão se processando no mundo globalizado.

Bauman (2001), utiliza o termo "modernidade líquida"7, trazendo à ideia "fluidez" e/ou "liquidez", como metáfora para se referir ao momento atual da

\footnotetext{
${ }^{7}$ Para Bauman (2001) fluidez, maleabilidade, flexibilidade e a capacidade de moldar-se em relação a infinitas estruturas, são algumas das características que o estado liquefeito confere às tantas esferas dos relacionamentos humanos por ele citados. O autor afirma que vivemos um tempo de transformações sociais aceleradas, nas quais as dissoluções dos laços afetivos e sociais são o centro da questão. A liquefação dos sólidos explicita um tempo de desapego e provisoriedade, uma suposta sensação de liberdade que traz em seu avesso a evidência do desamparo social em que se encontram os indivíduos moderno-líquidos.
}

Revbea, São Paulo, V. 10, N 1: 84-93, 2015. 
história da modernidade. Sua discussão parte da análise da sociedade atual e os problemas que dela demandam: o embate entre o indivíduo e o cidadão tendo a crescente individualidade e a consequente perda do sentimento de coletividade e comunidade; o consumismo e as consequências dele advindos; a busca pela liberdade, segurança e a emancipação; e o trabalho. Acredito que todos esses eventos descritos por Bauman se manifestam em uma temporalidade espacial, imbuída de paisagens perpassadas pelo espectro ambiental, onde se transcorrem os fenômenos sociais. A partir desse referencial, que tem como tema uma nova visão sobre a modernidade, voltada à fluidez das relações, do individualismo e do dinamismo, se faz necessário pensar num retrato da atual e imediatista sociedade fazendo uma analogia entre os "fluídos" propostos por Bauman (2001, p. 08) e os indivíduos: "[...] assim, para eles [indivíduos/fluídos], o que conta é o tempo, mais do que o espaço que Ihes toca ocupar; espaço que, afinal, preenchem apenas por um momento [...]".

Elias (1993), ensina que a sociedade é uma rede de funções e alerta que as mudanças nas formas de vida em sociedade independem do planejamento individual, sendo que ele existe só porque existe um grande número de pessoas e que ele só funciona porque muitas pessoas individualmente - querem e fazem certas coisas. $O$ autor coloca que a questão capital que permeia nossa sociedade é fato de como tornar possível criar uma ordem social que possibilite a harmonização ente o desenvolvimento pessoal do indivíduo e, por outro lado, pelas exigências feitas pelo trabalho coletivo de muitos no tocante à manutenção do social como um todo. Por mais que tentemos separar 0 indivíduo da sociedade, percebemos que 0 desenvolvimento de um está intimamente ligado ao do outro. Dessa forma, implicitamente, pode-se perceber que as ações geradas pelos indivíduos, a partir do trabalho, não como uma categoria marxista de análise, mas sim como o instrumento em que os espaços são apropriados e suas paisagens são transformadas, vão determinar, de certa forma, a conduta e a socialização desses indivíduos, imbuídos de funções $^{8}$ no seio de seu convívio social, podendo acarretar consequências em diversos níveis. Há de se pensar ainda, a partir de Elias, que as desigualdades em que se processam as relações entre os indivíduos, acabam gerando conflitos de ordem social, que acabam se manifestando em dimensões ambientais, como a perda da consciência éticoecológica, a falta de políticas públicas (ou a falta de vontade política?!) que atendam satisfatoriamente as necessidade e carências dos despossuídos componentes dessa sociedade formada por indivíduos.

\footnotetext{
${ }^{8}$ Norbert Elias (1996) diz que essa rede de funções existente nas associações humanas não surgiu à soma de vontades, isto é, da decisão comum das pessoas individuais. E, no entanto, esse contexto funcional é algo que existe fora dos indivíduos. Cada função é exercida de uma pessoa para outras. E cada uma destas funções está relacionada com terceiros: cada uma depende das outras. Portanto, é essa rede de funções que as pessoas desempenham umas em relação às outras, a ela e nada mais, chamamos sociedade.
} 
A rapidez na diminuição dos espaços em locomoção física ou sensorial é um dos mais claros exemplos do "derretimento" dos padrões que eram vigentes na modernidade sólida. Atualmente, computadores e telefonia, ambos móveis e portáteis, levam consigo a ordem e agenda de qualquer um a qualquer lugar, em ações que podem criar reações transformadoras (caóticas) de qualquer lugar para diversas posições do globo. Sobre esses aspectos Milton Santos (2004, p. 252) já dizia que "[...] a dinâmica dos espaços da globalização supõe uma adaptação permanente das formas e das normas [...]", assim sendo, "o espaço que, para o processo produtivo, une os homens, é o espaço que, por esse mesmo processo, os separa" (SANTOS 2004, p. 33).

Refletindo a partir do pensamento de Milton Santos acerca das imposições geradas pela globalização e pegando carona nas reflexões que Bauman (2001) tece sobre o atual estágio da sociedade, é possível constatar que um dos mais evidente e nocivo comportamento da sociedade é protagonizado e aflorado: o consumo. Nos últimos decênios, propagou-se um comportamento geral de comprar, não apenas produtos e serviços, mas também a aquisição de status junto às pessoas com quem os indivíduos se relacionam, seja o empregado, empregador ou até mesmo o par amoroso. Assim, esta sociedade é vista e se porta como consumidora, e não mais produtora, não existindo um limite para a busca da ostentação momentânea. Desde que se fuja à regra da padronização visual e comportamental os itens que simbolizam a ostentação agora, em pouco, tempo, se tornam itens de necessidade às próprias pessoas que, cada vez mais, deixam de adquirir bens para se entregar, viver para eles. Nessa busca pela satisfação pessoal, os indivíduos não têm levado em consideração a consciência ético-ecológica que privilegia a coletividade, trazendo à tona problemas em dimensões sócioeconômico-ambiental, que mantém inter-relações intrínsecas independentes do grau de intensidade e da ordem em que essas relações se processam.

As relações interpessoais, segundo Bauman, suspiram um saudosismo descaracterizado do pré-conceito do termo, que não se dá pelas interações entre os indivíduos, mas por uma busca da eficácia de mútua vigilância, de saber quem é você no limitado universo homogêneo de sua vizinhança. Nessa sociedade individualizada cria-se uma situação dúbia, pois ao mesmo tempo em que se investe em proteção, se fecha em "guetos", provocando o enclausuramento. Esses mesmos indivíduos buscam formas de expurgar os novos vilões da realidade-cela, a fim de gozar da liberdade com uma segurança almejada, trazendo à discussão o que Elias (1994), citado por Bauman (2001, p.39), nos apresenta no embate entre liberdade e dominação:

[...] a sociedade dando forma à individualidade de seus membros, e os indivíduos formando a sociedade a partir de

\footnotetext{
${ }^{9}$ Um outro termo usado por Bauman - derretimento - é empregado para designar a desintegração do discurso sólido e fixo já em vias de enferrujamento dos compostos institucionalizados da modernidade, como o pensamento cartesiano e a racionalidade instrumental, por exemplo. Agora, nessa nova modernidade maleável o que vigora é a ascensão de um objetivo individual, em declínio dessas instituições, analogamente, sólidas e tradicionalistas.
}

Revbea, São Paulo, V. 10, Nº 1: 84-93, 2015. 
suas ações na vida, enquanto seguem estratégias plausíveis e factíveis na rede socialmente tecidas de suas dependências.

Essa mutabilidade de relações também promove o desprendimento, no sentido afetivo e de posse eterna dos bens lucrativos, buscando-se sempre o "ter", o retorno financeiro; tendo em vista a noção de que os bens que são adquiridos são altamente perecíveis, descartáveis, voláteis e, decorrente a isto, são rapidamente rotacionados por aqueles que possuem condições de se incluir no circuito globalizante do consumo. Essa situação traz como conseqüências o consumismo, a maior demanda por fontes energéticas, a crescente extração de matérias-primas e o aumento na produção de rejeitos químicos/industriais/residenciais sem uma destinação adequada. Somados a esses fatores está a divisão que se impõe entre os que podem consumir e os não podem consumir, degradando ainda mais as relações sociais entre os indivíduos, como ensina Giddens (1997, apud BECK, GIDDENS e LASH, 1997, p. 233)

Assim, um grupo pobre pode viver juntamente com outro muito mais rico em, digamos, dois bairros vizinhos da mesma cidade; as privações de um podem ser causalmente relacionadas à riqueza do outro, mas não como uma conexão direta, nem mesmo talvez mediada pela sociedade nacional.

\section{Considerações finais}

De posse das considerações apontadas neste estudo, é possível afirmar que as implicações da crise paradigmática podem ser visualizadas na forma de como os espaços são apropriados e afetados pelos indivíduos/sujeitos, sendo transformados em lugares $\rightarrow$ espaços e espaços $\rightarrow$ lugares. Essas transformações metamorfoseiam-se, se exprimindo de maneira contundente nas paisagens, que são as partes visíveis desses espaços

A paisagem é história congelada, mas participa da história viva. São suas formas que realizam no espaço, as funções sociais. Assim pode-se falar, com toda legitimidade, de um funcionamento da paisagem [...] (SANTOS, 2004, p. 107). Se o conhecimento, como diz Whitehead (1938, p. 225), "nada mais é que a análise do funcionamento dos funcionamentos", então o conhecimento da paisagem supõe a inclusão de seu funcionamento no funcionamento global da sociedade. A paisagem é testemunha da sucessão dos meios de trabalho, um resultado histórico acumulado.

Dessa forma, a fim de se tentar entender a crise paradigmática em suas múltiplas manifestações, espera-se, ainda seguindo os passos de Milton Santos (2004, p. 107), que quando "[...] reconstruímos a história pretérita da paisagem, [...] a função da paisagem atual nos será dada por sua confrontação com a sociedade atual', seu modo de produção vigente e as relações e funções tecidas pelos indivíduos dessa/nessa sociedade. 
Acredita-se que a forma de conhecimento concebido pela modernidade não dará conta de responder às questões e aos anseios demandados pela sociedade atual, havendo a necessidade de se lançar novos olhares para as formas de se pensar o conhecimento. É preciso levar em consideração as redes complexas de relações que são tecidas no cotidiano, valorizando as dimensões dos saberes outrora multifacetadas, excluídas e tidas como não válidas pelas ciências modernas. Tentando apontar pistas para se romper com o enclausuramento provocado pela ciência moderna, Boaventura Santos (2000) nos mostra que o paradigma da modernidade comporta duas formas principais de conhecimento: o conhecimento-emancipação e o conhecimentoregulação. Segundo ele, o conhecimento-emancipação é tido como uma trajetória entre um estado de ignorância, designado pelo autor por colonialismo, e um estado de saber, designado por solidariedade. Já o conhecimentoregulação parte de um estado de ignorância, tido pelo autor como caos, para a um estado de saber designado por ordem.

De posse dessas tessituras realizadas construídas ao longo do texto, quais seriam os caminhos a percorrer na atual sociedade rumo à emancipação do indivíduo de jure, falso (BAUMAN, 2001), prisioneiro do conhecimentoregulação (BOAVENTURA SANTOS, 2000), capaz de transformá-lo em "sujeito encarnado "," indivíduo de fato (BAUMAN, 2000), que seja alcançado pelo conhecimento-emancipação (BOAVENTURA SANTOS, 2000)?

Por certo, esse caminhar perpassa pela complexa rede que se constitui na sociedade e que dela engloba todas as dimensões, desde a política, a educação, as relações familiares, etc., para, enfim desembocar na formação e constituição do sujeito, outrora percebido apenas como indivíduo, como engrenagem na então "máquina mundo" da modernidade.

Bauman (2001, p. 50).proclama a esperança, ao sugerir de como este sujeito pode emergir da situação atual que a sociedade o coloca a fim de se desvencilhar das amarras dessa modernidade outrora sólida:

O indivíduo de jure [falso] não pode se tornar indivíduo de facto sem antes tornar-se cidadão. Não há indivíduos autônomos sem uma sociedade autônoma, e a autonomia da sociedade requer uma auto-constituição deliberada e perpétua, algo que só pode ser uma realização compartilhada de seus membros

\section{Referências}

\footnotetext{
${ }^{10}$ Sobre esse conceito, com a palavra, Denise Najmanovich (2001, p. 28): "o sujeito encarnado é o nome de uma categoria heterogênea, facetada e de limites difusos. Uma categoria não clássica, já que os elementos que a formam não compartilham de uma propriedade comum, mas têm entre si um traço de família: O sujeito encarnado desfruta do poder da criatividade e da escolha, mas deve assumir o mundo que co-criou" (NAJMANOVICH, 2001, p.29).
}

Revbea, São Paulo, V. 10, Nº 1: 84-93, 2015. 
ALEXANDER, J.C. O Novo Movimento Teórico. Revista Brasileira de Ciências Sociais, número 4, volume 2, julho de 1987. p. 55-28 (www.cielo.br) BAUMAN, Z. Modernidade Líquida. Rio de Janeiro: Jorge Zahar editor, 2001. BECK, U.; GIDDENS, A.; LASH, S. Modernização reflexiva: política, tradição e estética na ordem social moderna. São Paulo: Editora Unesp; 1997.

BERGER, P.L.; LUCKMANN, T. A construção social da realidade. Petrópolis: Vozes, 1985.

BOURDIEU, P. O Poder Simbólico. Coleção Memória e Sociedade. Rio de Janeiro: Bertrand Brasil, 1989.

CAPRA, F. Sabedoria incomum. São Paulo: Cultrix, 1988.

CARVALHO, J.M. Do projeto às estratégias/táticas dos professores como profissionais necessários aos espaços/tempos da escola pública brasileira. In: CARVALHO, J.M. (org.). Diferentes perspectivas da profissão docente na atualidade. Vitória: EDUFES, 2004, pp. 10 - 44.

ELIAS, N. A sociedade dos indivíduos. Rio de Janeiro: Jorge Zahar Editor 1994.

MORIN, E. O método I: a natureza da natureza. $3^{\text {a }}$. ed. Portugal: Publicações Europa - América Ltda., 1997.

MORIN, E. O problema epistemológico da complexidade. $2^{\underline{a}}$ Ed. Portugal: Publicações Europa-América, 1996.

MORIN, E. A noção de sujeito. In: SCHNITMAN, D.F. (org.). Novos paradigmas, Cultura e Subjetividade. Porto Alegre: Artes Médicas. 1996.

NAJMANOVICH, D. O sujeito encarnado: Questões para pesquisa no/do cotidiano. Rio de Janeiro: DP\&A, 2001.

SANTOS, B.S. Um Discurso sobre as Ciências. 9aㅡ ed. Porto: Edições Afrontamento, 1997.

SANTOS, B.S. A crítica da razão indolente: contra o desperdício da experiência. São Paulo: Cortez, 2000.

SANTOS, B.S. (Org.). Conhecimento prudente para uma vida decente: "Um discurso sobre as ciências" revisitado. São Paulo: Cortez, 2004.

SANTOS, M. A Natureza do Espaço: Técnica e Tempo, Razão e Emoção. Coleção Milton Santos. 4⿳亠丷a edição. São Paulo: Editora da Universidade de São Paulo, 2004.

SANTOS, M. Pensando o Espaço do Homem. Coleção Milton Santos. 5 edição. São Paulo: Editora da Universidade de São Paulo, 2004.

SANTOS, M. Metamorfose do Espaço Habitado. 5ª edição. São Paulo: Ed Hucietec, 1997. 